American Journal of Pharmaceutical Education 2020; 84 (3) Article 7026.

\title{
RESEARCH
}

\section{Longitudinal Evaluation of the Healthy Living Assessment as an Experiential Learning Activity Provided On-Campus}

\author{
Catherine Langran, MPharm, Angela Alexander, PhD, BPharm, Parastou Donyai, PhD, BPharm \\ University of Reading, School of Pharmacy, Reading, Berkshire, United Kingdom \\ Submitted February 19, 2018; accepted August 7, 2019; published March 2020.
}

Objective. To implement and evaluate the effectiveness of healthy living assessments (HLA) conducted on campus by undergraduate pharmacy students.

Methods. Because of a shortage of workplace-based placements for undergraduate pharmacy students, a program was developed for students to conduct HLAs on campus for volunteer patients. Pharmacy students underwent training and completed a competency assessment before being approved to conduct HLAs. Staff members and students were recruited to serve as participants. Following the HLA, pharmacy students completed a quantitative and qualitative questionnaires to assess their perceived educational gains and opinions about the experience. Participants who underwent an HLA were asked to complete a questionnaire about the quality of the service they received.

Results. From 2011-2019, 896 HLAs were conducted by 764 undergraduate pharmacy students. The students reported that completing an HLA improved their clinical knowledge, counselling skills, professionalism, and confidence when talking to participants. They believed the HLA delivered an authentic learning experience, similar to that achieved during workplace-based placements. The HLA service was rated as good or outstanding by $99 \%$ of the participants, and the majority stated that they intended to make lifestyle changes as a result of attending the HLA.

Conclusion. Conducting healthy living assessments provided undergraduate pharmacy students a valuable, quality-assured opportunity for experiential learning. The HLAs were well received by participants as they informed them about their current health status and gave them useful advice about making health improvements.

Keywords: pharmacy, student-led, experiential learning, health

\section{INTRODUCTION}

In the United Kingdom, there are 31 accredited schools of pharmacy delivering a four-year Master of Pharmacy Degree (MPharm) program. ${ }^{1}$ After graduation, students complete one year of pre-registration training, usually in a community or hospital pharmacy. Pre-registration trainees must demonstrate their competence in terms of performance standards and pass a national end-of-year examination in order to register as a pharmacist with the General Pharmaceutical Council (GPhC). The GPhC also regulates the MPharm undergraduate curriculum and stipulates that it must include placements that provide students with experience working with patients. ${ }^{2}$ Placements deliver experiential learning which facilitates the

Corresponding Author: Catherine Langran, School of Pharmacy, University of Reading, Reading, Berkshire, RG6 6AP, UK. Tel: +44(0)1183787017. Email:

c.a.langran@reading.ac.uk development of student clinical skills and professional attitudes and behaviors. ${ }^{3-5}$

A 2018 survey of experiential learning in MPharm programs in the United Kingdom found that the total placement time at each university varies considerably, ranging from nine to 146 hours of community pharmacy placements and 14 to 103 hours of hospital pharmacy placements. ${ }^{6}$ Organizing placements for students can be challenging because of increasing class sizes, issues with obtaining and retaining placement providers, and lack of financial support, quality assurance measures, and/or administrative support. ${ }^{6}$ In the United States, introductory pharmacy practice experience (IPPE) programs have also experienced challenges such as competition for sites, difficulty conducting site visits, understaffing, and issues surrounding program assessment. ${ }^{7,8}$ Similar challenges with arranging placements for a large cohort of students (approximately 500 students) were experienced at Reading School of Pharmacy, leading to the introduction of an innovative approach involving on-campus placements. 


\section{American Journal of Pharmaceutical Education 2020; 84 (3) Article 7026.}

In 2011, funding was received from the University of Reading Alumni fund to establish a pilot program for undergraduate pharmacy students to conduct Healthy Living Assessments (HLAs). The HLAs were designed to give pharmacy students the opportunity to conduct diagnostic tests on volunteer participants to assess their cardiovascular risk and provide them with advice on healthy living. Delivering HLAs on campus was deemed feasible as it ensured no scheduling clashes, utilized the untapped resource of 19,000 university students and staff members to volunteer as participants, minimized costs, and could be fully quality assured. The aim of this study was to determine the perceived value of the HLAs to pharmacy students' learning and to the volunteer participants.

\section{METHODS}

The HLA was based on Health Check, a program of the UK National Health Service that includes measurement of blood pressure, blood cholesterol, blood glucose, and waist circumference; calculation of body mass index (BMI); assessment of alcohol use; assessment of wellbeing; questions about diet and smoking, and calculation of the participants' risk of developing heart disease and diabetes. ${ }^{9-12}$ Any member of the university staff or enrolled student over 18 years of age could undergo an HLA free of charge. The HLAs were advertised via emails to university staff members and students, on the student radio station, in the student newspaper, and on posters displayed around campus.

In September 2011, 48 third- and fourth-year undergraduate pharmacy students volunteered to participate in the HLA pilot program. Students attended two training sessions that lasted two hours each, completed a one-hour online assessment (had to receive a passing grade of $70 \%$ ), and conducted a mock HLA on staff members who provided formative feedback (two hours). Students who passed the training were deemed competent to undertake HLAs on volunteer participants. Students who did not achieve $70 \%$ in the online assessment attended an additional two-hour training session taught by the lead academic for the HLA program and then were retested.

The HLA pilot program was undertaken on 16 Wednesday afternoons from October 2011 to March 2012. From four to eight pharmacy students attended each session. They worked individually or in pairs to conduct the HLA on each participant. Each HLA typically took one hour, with students completing two to four HLAs per afternoon session. Throughout the HLA the students were supervised by academic staff members who were pharmacists, nurses, or nutritionists. Before the HLA session, all supervising staff members attended a two-hour briefing session with the HLA lead academic.
Following the success of this pilot, the HLA program was fully integrated into a clinical pharmacy module as a mandatory additional experiential placement for all fourth-year undergraduate pharmacy students. Students were required to complete the same training, online assessment, and mock HLA outlined above. Students then conducted an HLA individually or in pairs with one participant, typically spending up to 1.5 hours with the participant. Students were supervised by staff members as detailed previously. Because of scheduling challenges within the module, students were only able to complete one HLA on one participant. Starting in 2016, the HLA became an interprofessional learning activity, with an undergraduate Food and Nutritional Science student and a School of Pharmacy student paired together to complete the HLA. In this paper, we only report on the undergraduate pharmacy student evaluation. Also beginning in 2016, a body composition analysis and physical activity analysis (using the General Practice Physical Activity Questionnaire) were added to the HLA process. ${ }^{13}$

Several measures were embedded to ensure the safety and quality of each HLA. Standard operating procedures (SOPs) and risk assessments were written and followed. An information booklet with validated healthy lifestyle advice was provided to participants at the end of the HLA. ${ }^{14}$ Medical indemnity insurance was arranged for all students and supervising staff members. Only a trained academic faculty member or technical staff member with proof of hepatitis B immunity performed the finger prick and obtained the blood sample from the participant that were needed to conduct the cholesterol and glucose tests. Approval for this study was obtained from the University Research Ethics Committee. To ensure informed consent was obtained, volunteer participants were emailed an information sheet detailing the HLA process before the HLA session. Upon arrival, the process was reiterated verbally by the students and the participant was given an opportunity to ask questions. Participants could opt in or out of completing the HLA at that time, and were required to sign the consent form before beginning the HLA. Participants were given a written copy of their HLA results, verbal healthy living advice, and the health information booklet to take away. ${ }^{14}$ Participants with any results outside the reference ranges were referred to supervising staff members. The staff members checked to make sure that accurate measurements and interpretation of the result had taken place and then undertook a discussion with the participant and advised them to see their doctor.

After conducting the HLA, pharmacy students were asked to complete a questionnaire that included five questions regarding whether they felt completing the 


\section{American Journal of Pharmaceutical Education 2020; 84 (3) Article 7026.}

HLA improved their knowledge, clinical skills, counselling skills, confidence when talking to patients, and professionalism. Responses were based on a five-point Likert scale ranging from strongly agree to strongly disagree. Students were also asked to describe the differences between learning achieved from completing the HLA and learning achieved from current teaching methods (ie, lectures, problem-based learning, and workshops) or in their current workplace-based placements. An additional free-text box labeled "any other comments," was provided at the end of the questionnaire to capture any further comments from the students. Starting in 2016, students were also asked to complete a questionnaire evaluating the interprofessional learning in the HLA.

Participants who received an HLA were asked to complete a nine-item questionnaire about their experience. Participants answered the questions using a fivepoint Likert scale, with responses ranging from strongly agree to strongly disagree. The questionnaire asked participants to evaluate the service provided by the students, state how likely they were to make a change to their health, and provide an overall rating of the service. There was a free text box at the end of the questionnaire to capture any other thoughts the participants had about the HLA.

\section{RESULTS}

From 2011 to 2019, 764 undergraduate pharmacy students completed HLAs on volunteer participants. The response rate was $89 \%(n=683)$. The complete breakdown of student responses are presented in Table 1. All the results (from 2011 to 2019) have been collated to summarize that pharmacy students agreed that completing the HLA improved their knowledge (94\%), clinical skills (97\%), counselling skills (97\%), confidence talking to patients $(96 \%)$, and professionalism (95\%). Pharmacy students enjoyed completing the HLA (89\%) and valued the opportunity of a one-to-one or two-to-one consultation with the participant $(92 \%)$.

Student responses when comparing learning from conducting an HLA to existing teaching methods (lectures, PBL, and workshops) and workplace-based placements are presented as a summary here. Compared to lectures, students described the HLA as an opportunity to practically apply theoretical learning. Students enjoyed the active-learning activity the HLA provided and felt more academically engaged than they did during lectures. Students explained that this led them to remember and recall more of their learning. Students perceived learning that took place during problem-based learning (PBL) in the classroom and that during the HLA as similar, ie, both teaching methods involving critical thinking and the application of knowledge to patient care. However, students preferred the opportunity to interact with a person in the HLA compared to completing a paper-based case study. This made learning during the HLA more interesting for students compared to PBL and gave them a greater appreciation of the consequences of their advice. Students felt they developed more professionally during the HLA as they had more personal responsibility compared to when working in a group during PBL. Students reported that workshops were useful for practicing their technical and communication skills. Students stated that the interaction with people in the HLA further developed their communication and technical skills. Students said they felt more academically engaged and learned concepts

Table 1. Feedback of Pharmacy Undergraduate Students' on the Educational Benefits of Conducting Healthy Living Assessments

\begin{tabular}{|c|c|c|c|c|c|c|c|c|}
\hline & \multicolumn{8}{|c|}{ Academic Year } \\
\hline & $\begin{array}{l}2011- \\
12\end{array}$ & $\begin{array}{c}2012- \\
13\end{array}$ & $\begin{array}{c}2013- \\
14\end{array}$ & $\begin{array}{l}2014- \\
15\end{array}$ & $\begin{array}{l}2015- \\
16\end{array}$ & $\begin{array}{l}2016- \\
17\end{array}$ & 2017-18 & $\begin{array}{c}2018- \\
19\end{array}$ \\
\hline $\begin{array}{l}\text { Pharmacy students who completed the feedback } \\
\text { questionnaire, No. Response rate }(\%)\end{array}$ & $48(100)$ & $67(79)$ & $56(70)$ & $125(97)$ & $102(100)$ & $104(87)$ & $93(99)$ & $88(82)$ \\
\hline \multicolumn{9}{|c|}{$\begin{array}{l}\text { Students who agreed or strongly agreed that completing the training workshops and undertaking a healthy living assessment has } \\
\text { improved: No. }(\%) \text { : }\end{array}$} \\
\hline Clinical knowledge & $46(96)$ & $59(88)$ & $51(91)$ & $116(93)$ & $97(95)$ & $98(94)$ & $89(96)$ & $86(98)$ \\
\hline Clinical skills & $48(100)$ & $\mathrm{n} / \mathrm{a}$ & $\mathrm{n} / \mathrm{a}$ & $121(97)$ & $101(99)$ & $101(97)$ & $88(95)$ & $86(98)$ \\
\hline Counselling skills & $48(100)$ & $\mathrm{n} / \mathrm{a}$ & $\mathrm{n} / \mathrm{a}$ & $120(96)$ & $100(98)$ & $100(96)$ & $89(96)$ & $84(95)$ \\
\hline Confidence when talking to patients & $46(96)$ & $\mathrm{n} / \mathrm{a}$ & $\mathrm{n} / \mathrm{a}$ & $121(97)$ & $100(98)$ & $102(98)$ & $87(94)$ & $84(95)$ \\
\hline Professionalism & $45(94)$ & $\mathrm{n} / \mathrm{a}$ & $\mathrm{n} / \mathrm{a}$ & $120(96)$ & $98(96)$ & $103(99)$ & $84(90)$ & $82(93)$ \\
\hline I enjoyed the HLA session ${ }^{a}$ & $\mathrm{n} / \mathrm{a}$ & $59(88)$ & $51(91)$ & $\mathrm{n} / \mathrm{a}$ & $\mathrm{n} / \mathrm{a}$ & $\mathrm{n} / \mathrm{a}$ & $\mathrm{n} / \mathrm{a}$ & $\mathrm{n} / \mathrm{a}$ \\
\hline
\end{tabular}

${ }^{a}$ In 2012-13 and 2013-14 a different feedback questionnaire was used 


\section{American Journal of Pharmaceutical Education 2020; 84 (3) Article 7026.}

more in-depth during the HLA compared to in workshops. Students perceived the learning from the HLA to be most comparable to learning during workplace-based placements. Students expressed that both the HLA and placements combine the practical application of learning with patient interaction. The HLA gave students more time with participants and more responsibility because the students themselves performed and interpreted the tests. In contrast, students described that in some work-based placements they had just observed rather than assisted the pharmacist. A main difference that students noted was that, in workplace-based placements, they were offered a broader range of clinical experiences to learn from, whereas the HLA experience was focused and specific.

Qualitative student feedback reinforced the students' perceived value of this innovative experiential learning activity. Students described the HLA as well organized, enjoyable, a valuable experience to develop a variety of essential skills, and the "highlight of the course." As shown in Table 2, pharmacy students and Food and Nutritional Science students found that conducting the HLAs as an interprofessional activity encouraged shared learning, prepared them for future working relationships with other professionals, improved interprofessional team working skills, and improved cross-disciplinary communications skills.

From 2011 to 2019, a total of 896 HLAs were undertaken and $81 \%$ of participants completed a questionnaire at the end of their HLA evaluating the service they received $(n=724)$. The participant responses for each academic year are shown in Tables 3, 4, and 5. Participants reported the students were very welcoming (100\%); explained all the tests before the start of the HLA (98\%); carried out each test effectively (99\%); made them feel at ease (99\%); explained each test result thoroughly (99\%); gave them useful advice to improve their health (94\%); and helped them set personal goals to improve their health (83\%). Most participants $(71 \%)$ stated that they were planning on making a healthy lifestyle change as a result of attending the HLA. Overall, participants rated their HLA experience as outstanding (61\%), good (38\%), or adequate $(1 \%)$.

Qualitative comments from volunteer participants described the value of the peer approach of students delivering HLAs to other university students. Participants felt more comfortable talking about their health with fellow students than with their doctor and felt the advice given was tailored to student lifestyles. The HLA had a positive effect on participants by making them more aware of their health. Participants thought it was a "brilliant service" that was "run by very friendly and competent students." Participants valued the accessibility of the HLA sessions, for example, staff were able to have an HLA at work during their lunch break.

\section{DISCUSSION}

This paper demonstrates that, over the eight years the HLA sessions have been conducted, the program has consistently delivered valuable experiential learning for pharmacy students, supporting development of their knowledge, skills, and professional behaviors. Compared to didactic teaching methods, the HLA is an active method of learning. It requires that undergraduate students understand the theory behind each diagnostic test

Table 2. Feedback From Pharmacy and Food and Nutritional Science Students on Interprofessional Learning During a Healthy Living Assessment

\begin{tabular}{llcrr}
\hline & & \multicolumn{3}{c}{ Academic Year } \\
\cline { 3 - 5 } & & $\mathbf{2 0 1 6 / 1 7}$ & $\mathbf{2 0 1 7 / 1 8}$ & $\mathbf{2 0 1 8 / 1 9}$ \\
\hline Number of students who undertook an HLA & Pharmacy & 119 & 94 & 107 \\
& FNS & 38 & 63 & 75 \\
Number of students who completed the IPL & Pharmacy & $107(90)$ & $77(82)$ & $63(59)$ \\
$\quad$ feedback questionnaire (response rate \%) & FNS & $32(83)$ & $43(68)$ & $52(69)$ \\
Students who agreed or strongly agreed that completing & the training workshops and undertaking a healthy living assessment has: \\
Encouraged shared learning, No. (\%) & Pharmacy & $101(94)$ & $58(75)$ & $57(90)$ \\
& FNS & $29(91)$ & $32(74)$ & $45(87)$ \\
Prepared me for future working relations with & Pharmacy & $100(93)$ & $64(83)$ & $58(92)$ \\
$\quad \begin{array}{l}\text { other health care professionals/ collaborative } \\
\text { practice }\end{array}$ & FNS & $30(94)$ & $35(82)$ & $44(85)$ \\
Improved my interprofessional team working & Pharmacy & $103(96)$ & $64(83)$ & $57(90)$ \\
$\quad$ skills & FNS & $32(100)$ & $37(86)$ & $44(85)$ \\
Improved my communication skills within an & Pharmacy & $100(93)$ & $62(81)$ & $58(92)$ \\
$\quad$ interprofessional team & FNS & $30(94)$ & $35(82)$ & $46(88)$ \\
\hline
\end{tabular}

Abbreviations: FNS $=$ Food and Nutritional Science 
American Journal of Pharmaceutical Education 2020; 84 (3) Article 7026.

Table 3. Feedback of Volunteer Participants in Healthy Living Assessments Conducted by Pharmacy Students

\begin{tabular}{|c|c|c|c|c|c|c|c|c|}
\hline & \multicolumn{8}{|c|}{ Academic Year } \\
\hline & 2011/12 & 2012/13 & 2013/14 & 2014/15 & $2015 / 16$ & 2016/17 & $2017 / 18$ & 2018-19 \\
\hline HLAs completed, No. & 381 & 94 & 80 & 72 & 48 & 61 & 81 & 79 \\
\hline $\begin{array}{l}\text { Participants who completed the feedback } \\
\text { questionnaire, No. }(\%)\end{array}$ & $261(69)$ & $72(77)$ & $74(93)$ & $66(92)$ & $44(92)$ & $56(92)$ & $74(91)$ & $77(97)$ \\
\hline \multicolumn{9}{|c|}{ Participants who agreed or strongly agreed that pharmacy students: No. (\%) } \\
\hline Were very welcoming & $260(99)$ & $72(100)$ & $74(100)$ & $66(100)$ & $44(100)$ & $56(100)$ & $74(100)$ & $77(100)$ \\
\hline $\begin{array}{l}\text { Explained all the tests to me before the start } \\
\text { of the health check }\end{array}$ & $253(97)$ & $72(100)$ & $72(97)$ & $65(98)$ & $44(100)$ & $55(98)$ & $73(99)$ & $76(99)$ \\
\hline Carried out each test efficiently & $259(99)$ & $71(99)$ & $73(99)$ & $66(100)$ & $44(100)$ & $55(98)$ & 73 (99) & $77(100)$ \\
\hline Made me feel at ease & $257(98)$ & $72(100)$ & $74(100)$ & $66(100)$ & $44(100)$ & $56(100)$ & $74(100)$ & $77(100)$ \\
\hline Explained each test result thoroughly & $255(98)$ & $72(100)$ & $74(100)$ & $66(100)$ & $44(100)$ & $55(98)$ & $73(99)$ & $76(99)$ \\
\hline Gave me useful advice to improve my health & $237(91)$ & $70(97)$ & $73(99)$ & $65(98)$ & $41(93)$ & $56(100)$ & $68(92)$ & $74(96)$ \\
\hline $\begin{array}{l}\text { Helped me set personal goals to improve my } \\
\text { health }\end{array}$ & $203(78)$ & $60(93)$ & $68(92)$ & $60(91)$ & $36(82)$ & $50(89)$ & $59(80)$ & $67(87)$ \\
\hline
\end{tabular}

and then apply this learning throughout the HLA. For example, when explaining test results to participants and negotiating health goals with them. While workshops (eg, measuring blood glucose) and PBL (eg, creating a care plan for a diabetic patient) are useful to develop understanding and application of knowledge, students may not consider them to be as authentic as the HLAs. For authentic learning to occur, a combination of context, concept, and activity is required. ${ }^{15}$ Even if an authentic activity (eg, measuring glucose or creating a care plan) is used, if conducted in a classroom-based workshop the context is altered. The activity becomes just another workshop task. Students learn about the topic so they can perform well in the workshop and pass the examination rather than so they will know how to care for a patient. ${ }^{16}$ Concepts only become meaningful, relatable, and transferrable when students see them being used and are able to apply them in real-life situations. ${ }^{3}$ The HLA provides the context (working with people), the concept (to improve their consultation and clinical skills), and the activity (eg, measuring glucose) for authentic learning to occur. The most significant finding was undergraduate pharmacy students describing the HLA as an equivalent learning experience to workplace-based placements, demonstrating that on-campus experiential learning can be perceived as being as educationally valid as external experiential learning.

Incorporation of the HLAs into the fourth-year undergraduate pharmacy module allowed constructive alignment; pharmacy students undertake the HLA to achieve set learning outcomes and then their knowledge and skills are assessed in a summative objective structured clinical examination (OSCE) at the end of the year. Undertaking the HLA as a mandatory learning activity supports transitioning the pharmacy students from the "knows how" level of Miller's framework for clinical assessment to the "does" level. ${ }^{17}$ As a final year activity, it is well placed to prepare graduates with essential clinical skills for their pre-registration training year.

Undertaking the HLAs also facilitated undergraduate pharmacy student's development of employability skills, such as personal effectiveness (eg, they had to

Table 4. Volunteer Participants' Intention to Make a Lifestyle Change as a Result of Undergoing a Healthy Living Assessment by and Receiving Advice From a Pharmacy Student, No. (\%)

\begin{tabular}{lcccccccc}
\hline & \multicolumn{7}{c}{ Academic Year } \\
\cline { 2 - 8 } Response Options & $\mathbf{2 0 1 1 / 1 2}$ & $\mathbf{2 0 1 2 / 1 3}$ & $\mathbf{2 0 1 3 / 1 4}$ & $\mathbf{2 0 1 4 / 1 5}$ & $\mathbf{2 0 1 5 / 1 6}$ & $\mathbf{2 0 1 6 / 1 7}$ & $\mathbf{2 0 1 7 / 1 8}$ & $\mathbf{2 0 1 8 / 1 9}$ \\
\hline Yes, definitely & $134(51)$ & $51(71)$ & $44(60)$ & $40(61)$ & $30(68)$ & $39(69)$ & $49(66)$ & $51(66)$ \\
Yes, but not yet & $39(15)$ & $7(10)$ & $6(8)$ & $5(7)$ & $2(5)$ & $6(11)$ & $9(12)$ & $8(10)$ \\
Maybe & $42(16)$ & $9(12)$ & $6(8)$ & $9(14)$ & $5(11)$ & $6(11)$ & $9(12)$ & $9(12)$ \\
Definitely not & $4(2)$ & 0 & 0 & $1(1)$ & 0 & 0 & 0 & 0 \\
$\begin{array}{l}\text { Not applicable as no improvements were } \\
\quad \text { identified }\end{array}$ & $42(16)$ & $5(7)$ & $18(24)$ & $11(17)$ & $7(16)$ & $5(9)$ & $7(10)$ & $9(12)$ \\
& & & & & & & &
\end{tabular}

a The actual wording of the survey item was as follows: "Are you planning on making any lifestyle changes to improve your health as result of your healthy living assessment results and advice given?" 
American Journal of Pharmaceutical Education 2020; 84 (3) Article 7026.

Table 5. Volunteer Participants' Overall Rating of the HLA Provided by Pharmacy Students

\begin{tabular}{lcccccccc}
\hline & \multicolumn{7}{c}{ Academic Year } \\
\cline { 2 - 10 } Response Options & $\mathbf{2 0 1 1 / 1 2}$ & $\mathbf{2 0 1 2 / 1 3}$ & $\mathbf{2 0 1 3 / 1 4}$ & $\mathbf{2 0 1 4 / 1 5}$ & $\mathbf{2 0 1 5 / 1 6}$ & $\mathbf{2 0 1 6 / 1 7}$ & $\mathbf{2 0 1 7 / 1 8}$ & $\mathbf{2 0 1 8 / 1 9}$ \\
\hline \multirow{2}{*}{ Outstanding } & $131(50)$ & $45(63)$ & $40(54)$ & $47(71)$ & $36(82)$ & $39(70)$ & $47(64)$ & $56(73)$ \\
Good & $126(48)$ & $27(37)$ & $33(45)$ & $19(29)$ & $8(18)$ & $17(30)$ & $26(35)$ & $21(27)$ \\
Adequate & $4(2)$ & 0 & $1(1)$ & 0 & 0 & 0 & $1(1)$ & 0 \\
Poor & 0 & 0 & 0 & 0 & 0 & 0 & 0 & 0 \\
\hline
\end{tabular}

manage the time they had), decision-making and problem-solving (eg, providing participants with options to improve their health and helping them select the most appropriate ones) and people skills (eg, making participants feel at ease, communicating sensitive information, negotiating health changes). Employers consider these skills to be among the most important when recruiting graduates. ${ }^{18}$

Over the past eight years, 896 HLAs have been conducted for volunteer participants on campus. The HLAs have consistently been highly rated (83\%-100\%) in terms of student behaviors (eg, welcoming manner, making participants feel at ease, efficiency and ability to undertake and explain tests and results, healthy living advice giving and agreeing health goals). The majority $(72 \%)$ of participants stated that they were intending to make lifestyle changes as a result of the HLA. This signifies how undergraduate students can positively influence participants' knowledge and attitudes with regards to health behaviors. The HLA service was consistently rated as a good or outstanding service (99\%), demonstrating a high-quality service with rigorous training and quality assurance processes.

There are several limitations to this research. No data related to baseline undergraduate student competence or attitudes were collected. Also, there was no control group of students, so comparisons of skill acquisition could not be made. The HLA relied upon university staff members and students to volunteer to be participants, potentially biasing the sample towards well-educated members of the population. Also, participants may have known the student providing their care. Only those who were interested in their health volunteered to be participants; thus, their feedback may have been skewed to be more positive as they may have already been considering making changes to their lifestyle. Part of the ethical approval for the HLA involved maintaining participants' confidentiality and participant identifiable data (name, date of birth, contact details) were not recorded. Therefore, it was not possible to follow-up with participants to ask whether they had implemented healthy lifestyle changes and whether they would be willing to undergo the HLA again to establish whether their test results had improved. Thus, it cannot be claimed that the HLA made a sustained impact on the participants' health.

This on-campus experiential learning activity can be replicated in other schools of pharmacy. Globally, there is evidence to support that pharmacy student-led health education initiatives, such as diabetic checks and community wellness and disease prevention programs, are well-received and valuable to the local communities . ${ }^{19-21}$ These global pharmacy student led services demonstrate that undergraduate pharmacy students have the competence to undertake patient-care. We believe we were the first UK pharmacy school to initiate this experiential activity on campus. Pharmacy schools in the United Kingdom offer a wide range of external experiential learning in hospitals, community pharmacies, prisons, care homes, and hospices, but these placements come with the challenges of obtaining and retaining placement providers, quality assurance, and cost. ${ }^{6}$ The on-campus HLAs do not replace external placements for pharmacy student, but rather facilitate increased experiential learning in a lowcost, standardized, and quality-assured manner. In 2018, the HLA experience and resources were shared with another UK pharmacy school to support them in piloting student-led health checks. ${ }^{22}$ Potential future work could be to conduct HLAs in a more diverse population, for example, in local community centers, and to work with local health organizations to commission undergraduate pharmacy students to deliver HLAs on their behalf.

\section{CONCLUSION}

This paper demonstrates the sustainability of the HLA as an experiential learning activity, the educational benefits of the HLA program for students, and the potential health benefits of the program for participants. Student feedback validated that conducting an HLA is as an authentic and valuable learning experience. The HLA positively influenced their clinical skills, professionalism, and consultation skills, which will benefit them during the MPharm program and beyond. The HLAs were well received by participants, demonstrating the value of 


\section{American Journal of Pharmaceutical Education 2020; 84 (3) Article 7026.}

a student-led health initiative. Providing participants with their test results and giving them healthy living advice encouraged participants to consider making lifestyle changes.

\section{ACKNOWLEDGMENTS}

Funding was provided by the University of Reading Alumni fund in 2011. We are grateful to Kat Hall, Director of the Centre for Inter-Professional Postgraduate Education \& Training at University of Reading, for proofreading.

\section{REFERENCES}

1. General Pharmaceutical Council (GPhC). Providers of GPhC accredited Mpharm degrees https://www.pharmacyregulation.org/ education/pharmacist/accredited-mpharm-degrees. Accessed March $19,2020$.

2. General Pharmaceutical Council. Standards for the Initial Education and Training of Pharmacists. May 2011.

3. McKeachie WJ. Mckeachie's Teaching Tips; Strategies, Research and Theory for College and University Teachers. $11^{\text {th }}$ Edition. College Teaching Series. 2002.

4. Fry H, Ketteridge S, Marshall S. A Handbook for Teaching and Learning in Higher Education. $3^{\text {rd }}$ edition. Routledge. 2009.

5. Colley H, James D, Tedder M, Diment K. Learning as becoming in vocational education and training: class, gender and the role of habitus. Journal of Vocational Education and Training. 2003;(55) 4:471-497.

6. Jacob SA, Boyter AC. Nationwide survey of experiential learning in MPharm programmes in UK Universities. International Journal of Pharmacy Practice. 2019

7. Devine PS, Darbishire PL. National trends in IPPE programs at US schools of pharmacy from 2008-2013. Am J Pharm Educ. 2015;79(3):39.

8. Darbishire PL, Devine T, Holowatyj MR, Schmelz AN. National Survey of Introductory Pharmacy Practice. Scholarship and
Professional Work - COPHS. 187. 2008. http:// digitalcommons.butler.edu/cophs_papers/187. Accessed March 19, 2020.

9. National Health Service. NHS Health Check. www.healthcheck.nhs.uk. Accessed March 19, 2020. 10. World Health Organization. The Alcohol Use Disorders Identification Test. Guidelines for Use in Primary Care. Department of Mental Health and Substance Dependence. $2^{\text {nd }}$ Edition. 2001.

11. Education Support Partnership. Wheel of wellbeing test. https:// www.educationsupportpartnership.org.uk/resources/online-tools/ wheel-wellbeing-test. Accessed March 19, 2020.

12. ClinRisk Ltd. Q-RISK 3 algorithm 2018. https://qrisk.org/three/. Accessed March 19, 2020.

13. Department of Health and Social Care. General Practice Physical Activity Questionnaire (GPPAQ). April 2013.

14. British Heart Foundation. Keep your heart healthy. 2014. https:// www.bhf.org.uk/publications/heart-conditions/keep-your-hearthealthy. Accessed March 29, 2020.

15. Brown JS, Collins A, Duguid. Situated cognition and the culture of learning. Educational Researcher. 1989;(18)132-142.

16. Lave J, Wenger E. Situated Learning, Cambridge University Press, Cambridge. 1991

17. Miller G. The assessment of clinical skills/competence/ performance. Academic Medicine. 1990;65(9):s63-s67.

18. Confederation of British Industry's \& Universities UK Future Fit: Preparing graduates for the world of work. 2009.

19. Guirguis LM, Chewning BA, Kieser MA, Kanous NL.

Evaluation of structured patient interactions: the diabetes check. Am J Pharm Educ. 2006;70(3).

20. Lee BJ, Wang SK, So C. A student-led health education initiative addressing health disparities in a Chinatown community. Am J Pharm Educ. 2015;79(9).

21. Offiong CY, Oji VU, Bunyan W, Lewis JA, Moore M, Olusanya $\mathrm{OA}$. The role of colleges and schools of pharmacy in the advent of Healthy People 2020. Am J Pharm Educ. 2011;75(3).

22. Medlinskiene K, Tomlinson J. Piloting an undergraduate studentled health check service. Clinical Pharmacist. 2019;(11)5. 